\title{
The New Internet Discourse of Healthcare in Turkish Hospitals' Social Media Pages
}

\section{EIgiz Yılmaz, Galatasaray University, Turkey}

\begin{abstract}
In this paper, discourse analysis of health is concerned with a critical analysis of the language use and the reproduction of dominant institutional ideologies in Turkish hospitals' Facebook pages exploring the way in which health beliefs and the dissemination of health information are coded in the new media.
\end{abstract}

This paper aims to analyze the various discourses of healthcare on Turkish hospitals' Facebook pages using "Sosyomod" new media monitoring tool. Analyzing identified health topics on these pages offers a substantial contribution to the growing field of health literacy in online health communication. How do hospitals describe their health concerns and ask for information and advice? In answering these questions, the new Internet discourse of healthcare takes an interdisciplinary approach to discourse analysis, corpus linguistics and recent work in computer-mediated communication, and shows how these fields interplay in establishing new frameworks for health communication and health literacy researches.

Key words: internet discourse, discourse of healthcare, hospital, health literacy. 


\section{Introduction}

Health communication is about communicating and computer technology has revolutionized communications. In many ways, the Internet and digital technologies have helped to reduce the psychological distance that exists between an organization and the publics that impact its success. As if Internet has become the organizations' new front door, their target audiences are directed to various information sites within the corporate web site. Corporations have options to deliver their messages to highly targeted audiences with advanced multimedia platforms such as corporate websites, interactive media tools which aim to convert a casual visitor to a customer and then to a business partner.

The emergence and increasing popularity of social media have changed the practice of health communication. Social media offer numerous opportunities for health communication practitioners to interact with a wide range of stakeholders. Because of the prominent organizations engaging in social media and the growing popularity of social media among various communities, companies are becoming more involved in trying to measure and manage social media. Social media sites are virtual platforms for interactivity and information exchange (Perlmutter, 2008) where users collaborate in content creation and participation. Health organizations use social media to increase interactions with publics through a steady flow of inputs and outputs (Sundar, 2005) )towards mutually beneficial relationships (Yang \& Lim, 2009; 343).

\section{Health Communication and New Communication Technologies}

New information and communications technologies (ICTs) hold promise for the creation of effective and innovative health promotion (Thackeray, Neiger, Hanson, \& McKenzie, 2008). Researchers argue that social media forms (which they define as email, texting, microblogging, and smartphone applications) can be used by health professionals to increase health engagement and improve health outcomes (Fisher \& Clayton, 2012). Social media sites encourage self-expression, users may be more interested in representing an issue and belonging to a community than communicating personal insight, a perspective that contradicts accepted definitions of social media as a tool for self-expression (Rettberg, 2009; 452). Social media tools that facilitate issue alliance (i.e. retweets, forwards, "like" applications), may lead to more interactivity for their facilitation of user association with an issue. Thus, functional 
interactivity is based on an application's ease of use in connecting a user to his or her intended interest.

In particular, Fisher and Clayton (Fisher \& Clayton, 2012) state that future studies need to consider patient's media preferences and their level of interest in the use of social media for health care. We argue that understanding users' preferences regarding different sources of health-promotion media, including ICTs, is an essential component of effective health communication (Halpert et al., 2008). Digital technologies, including ubiquitous mobile devices, can play a key role in transforming health care system on-demand access to the medical records and powerful clinical decision support tools that empower patients to actively participate in their treatment plans (Doğanyiğit \& Y1lmaz, 2015).

RQ: How do hospitals describe their health concerns and ask for information and advice, and how do healthcare professionals' online services are offered?

\section{Methods and Procedures}

Discourse analysis is an interdisciplinary field of inquiry which has been little employed by public health practitioners. The methodology involves a focus upon the sociocultural and institutional context in which text and talk occur. What distinguishes a discourse analytical perspective from other approaches to health is its focus on "language in use," that is, on the way people use discourse as a tool to take concrete social actions. This focus is especially suited to the domains of health.

By the growing importance of social media in today's world, brands will be able to follow the traces of their target audiences through developing monitoring tools and to keep up with their customer needs. In this paper, we have examined Turkish public and private hospitals' Facebook profiles via Sosyomod monitoring tool. Sosyomod is a website and social media monitoring tool which allows brands to read "big data" and identify their specific target audiences, thus to get insights about their needs through detailed analysis. With Sosyomod, all brand categories could monitor big data, described as large volume of data structured, processed and gathered from the internet and the social media in time, could develop business model and implement target -oriented communication with their consumers. 
The findings obtained by Sosyomod indicated that 408 of the Turkish public and private hospitals, the universe of the study, have Facebook business accounts. The Facebook accounts of the hospitals that describe themselves as "hospital" in their profile description, whereas they do not offer health care service, were cleared and the research universe were limited to 308 hospitals. Sosyomod has performed following tracking for the 308 hospital profiles between the dates 01.01.2016 and 01.05.2016:

- The regional impact analysis of Turkish public and private hospitals' Facebook pages by their number of likes,

- Keywords used related to health among the hospitals' Facebook posts and number of posts including the keywords related to health,

- Number of times keywords used in users' comment on the hospitals' posts,

-Categories selected by hospitals while creating Facebook business accounts,

- Keywords selected by hospitals to define "about/description" section on Facebook pages and

- Number of posts and comments per hour/day.

\section{Results}

Quantitative and descriptive question sections are presented in the coding scheme illustrating how 308 hospitals use their Facebook business pages. To set an example, question sections were prepared concerning Facebook account type, account information, profile information, number of posts, number of likes on the posts, number of comments on the posts, number of posts with published date and time, distribution of posts per hours and distribution of posts "seen" and "interacted" by users per hours and, the most used 24 keywords. 
Graphic 1: The regional impact analysis of Turkish public and private hospitals' Facebook pages by their number of likes

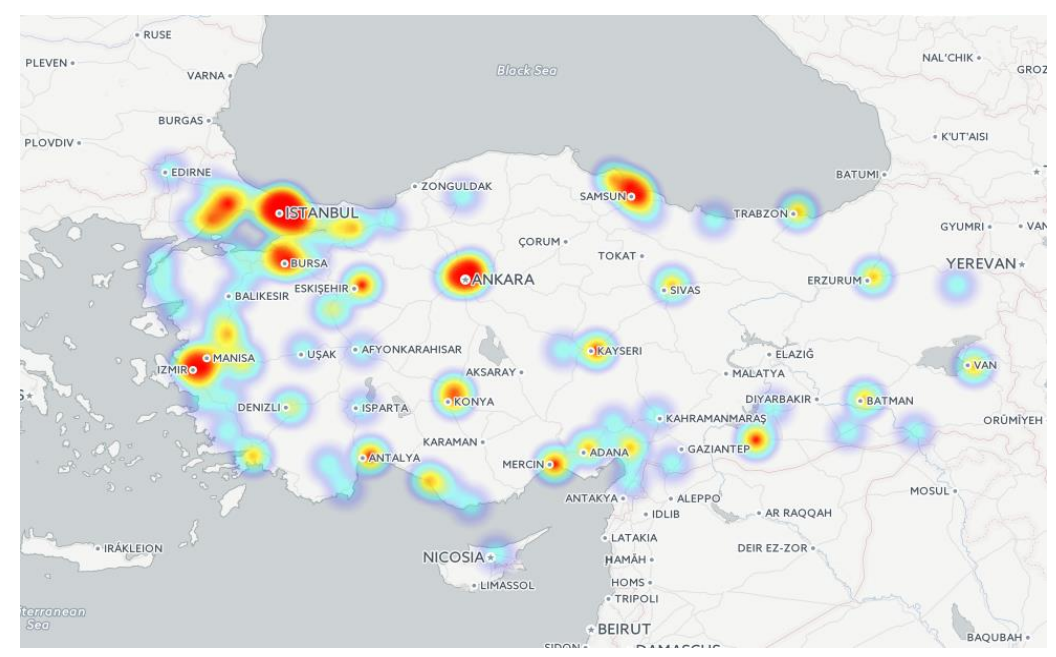

Source: Gathered from Sosyomod (10.05.2016)

Basing on the map above, we see that the most "liked" Facebook pages among the 308 hospitals are the hospitals densely locating in Turkey's metropolises such as İstanbul, Tekirdağ, Samsun, Ankara, Bursa, İzmir, Konya, Mersin, Gaziantep, Kayseri and Eskişehir. We could assert that the impact distribution by "like" numbers shows consistency with hospital investment plans realized by public-private partnership of the Ministry of Healthy.

With Sosyomod, we tracked the most frequently searched following 24 keywords about healthy to figure out the content of the posts shared by the most "liked" hospital pages across the Turkey: health, happiness, polyclinic, consultation, doctor, home care, visit, lab, treatment, operation, baby, birth, cesarean, child, by-pass, obesity, cancer, allergy, well nutrition, fitness, laser epilation, hair transplant, eye brow filler, aesthetic.

Table 1: List of keywords used among the hospitals' posts and the number of times "keywords" used in posts

\begin{tabular}{|l|l|}
\hline Health & 10242 \\
\hline Treatment & 5022 \\
\hline Child & 3514 \\
\hline Physician & 2918 \\
\hline
\end{tabular}




\begin{tabular}{|l|l|}
\hline Baby & 2693 \\
\hline Birth & 2381 \\
\hline Operation & 2335 \\
\hline Cancer & 1903 \\
\hline Visit & 1682 \\
\hline Consultation & 1100 \\
\hline Happiness & 1064 \\
\hline Obesity & 743 \\
\hline Fitness & 725 \\
\hline Aesthetic & 673 \\
\hline Well nutrition & 500 \\
\hline Polyclinic & 355 \\
\hline Allergy & 342 \\
\hline Hair transplant & 217 \\
\hline Laser epilation & 191 \\
\hline Lab & 190 \\
\hline Cesarean & 100 \\
\hline Home care & 41 \\
\hline By-pass & 28 \\
\hline Eyebrow filler & 2 \\
\hline
\end{tabular}

\section{Source: Gathered from Sosyomod (10.05.2016)}

Having analyzed the most frequently used keywords among the 308 hospitals' Facebook posts, it has been revealed that basic expressions concerning health services such as health, doctors, treatment, and visit are stated to admit more patients to hospitals. In addition to it, it has been observed that since the most frequently used keywords on the posts refer to child, baby, birth, operation and cancer, the surveyed hospitals focus on services for cancer diagnosis and treatment along with gynecology and pediatrics. 
Table 2: List of keywords used in users' comments and the number of times keywords used in users' comments

\begin{tabular}{|l|l|}
\hline Health & 7599 \\
\hline Physician & 7595 \\
\hline Treatment & 2622 \\
\hline Operation & 2100 \\
\hline Child & 1558 \\
\hline Consultation & 982 \\
\hline Cancer & 931 \\
\hline Birth & 928 \\
\hline Baby & 679 \\
\hline Fitness & 562 \\
\hline Happiness & 312 \\
\hline Visit & 290 \\
\hline Allergy & 272 \\
\hline Obesity & 247 \\
\hline Cesarean & 242 \\
\hline Well nutrition & 138 \\
\hline Lab & 105 \\
\hline Polyclinic & 69 \\
\hline Aesthetic & 63 \\
\hline Hair transplant & 29 \\
\hline Home care & 5 \\
\hline Laser epilation & 0 \\
\hline By-pass & 14 \\
\hline Eyebrow filler & 28 \\
\hline
\end{tabular}

Source: Gathered from Sosyomod (10.05.2016)

According to users' comment on the posts shared by 308 hospitals, the most frequently used keywords listed in the Table 1 are basic health expressions like health, doctors, treatment, consultation and visit and services for cancer diagnosis and treatment along with gynecology and pediatrics. 
Table 3: Lists of categories selected by hospitals while creating Facebook business accounts

\begin{tabular}{|l|l|}
\hline Local Business & 84 \\
\hline Hospital/Clinic & 74 \\
\hline Health/Medical/Pharmaceuticals & 56 \\
\hline Government Organization & 22 \\
\hline Product/Service & 21 \\
\hline Company & 11 \\
\hline Health/Medical/Pharmacy & 9 \\
\hline Community & 3 \\
\hline Health/Beauty & 2 \\
\hline Business Person & 1 \\
\hline Computers/Technology & 1 \\
\hline Doctor & 1 \\
\hline Museum/Art Gallery & 1 \\
\hline Other & 1 \\
\hline Personal Website & 1 \\
\hline
\end{tabular}

Source: Gathered from Sosyomod (10.05.2016)

Although hospitals, as health care facilities, operate within a certain area, it has been seen on their Facebook profiles that there is no common business category chosen by hospitals. Hospitals often describe their business categories on Facebook as local business, hospital/clinic ve health/medical/pharmaceuticals. 
Graphic 2: List of keywords selected by hospitals to define "about/description" section on their Facebook pages

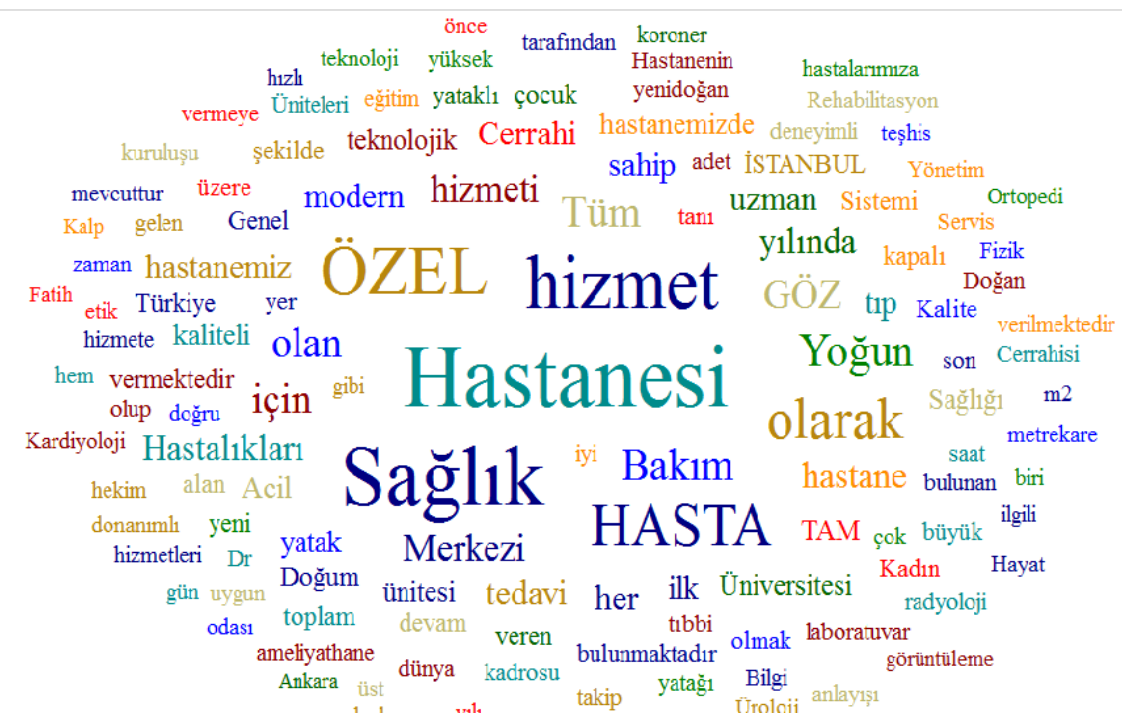

Source: Gathered from Sosyomod (10.05.2016)

In line with the hospitals' business category descriptions on their Facebook pages, as indicated in Table 3, such keywords as health, hospital, patient, service and private were preferred in "about" section of these pages. Because of the dominant word "private" glaring from "word cloud" and pharmaceutical industry regulations, it seems that private health care facilities are more inclined to join the Facebook social networking site.

Graphic 3: Number of posts and comments per hour/day

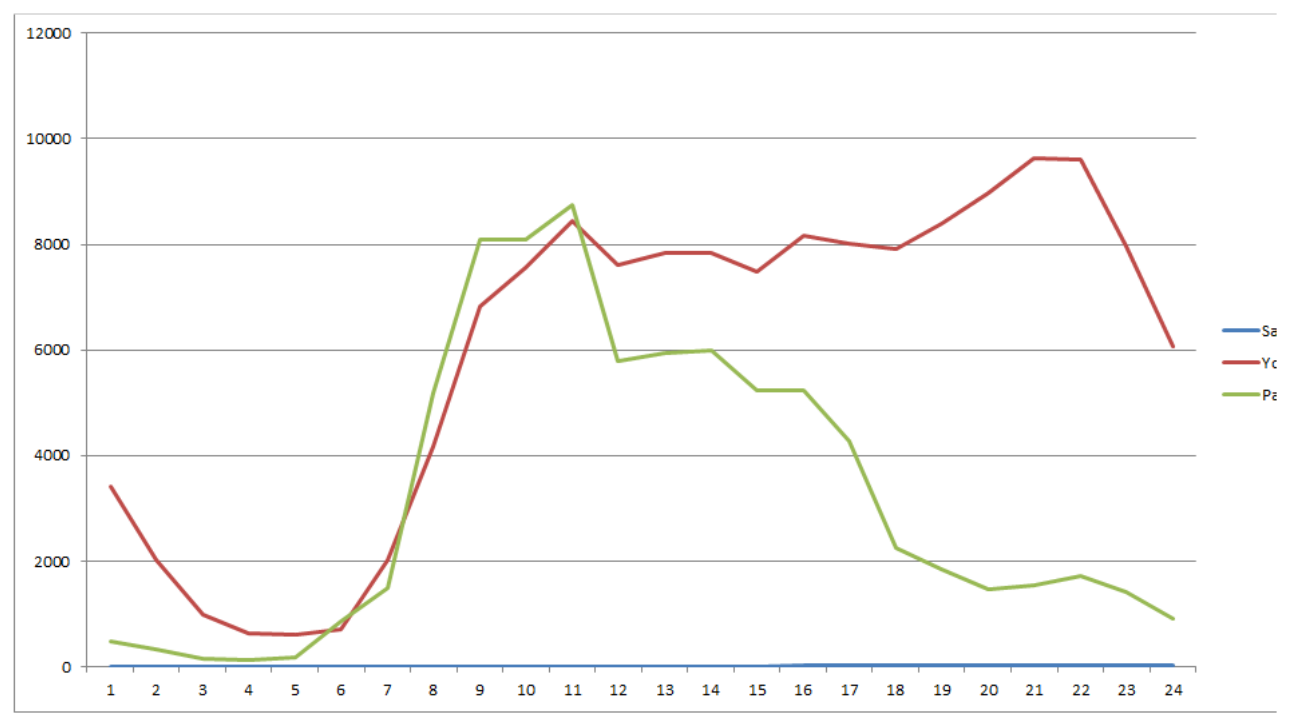




\begin{tabular}{|c|c|c|}
\hline Hour & Comment & Post \\
\hline 1 & 3416 & 493 \\
\hline 2 & 2028 & 333 \\
\hline 3 & 998 & 165 \\
\hline 4 & 633 & 118 \\
\hline 5 & 617 & 189 \\
\hline 6 & 703 & 867 \\
\hline 7 & 2028 & 1505 \\
\hline 8 & 4165 & 5176 \\
\hline 9 & 6829 & 8093 \\
\hline 10 & 7560 & 8095 \\
\hline 11 & 8447 & 8745 \\
\hline 12 & 7602 & 5784 \\
\hline 13 & 7842 & 5944 \\
\hline 14 & 7835 & 5982 \\
\hline 15 & 7472 & 5231 \\
\hline 16 & 8178 & 5231 \\
\hline 17 & 8008 & 4282 \\
\hline 18 & 7924 & 2253 \\
\hline 19 & 8388 & 1857 \\
\hline 20 & 8969 & 1460 \\
\hline 21 & 9630 & 1547 \\
\hline 22 & 9607 & 1730 \\
\hline 23 & 7965 & 1430 \\
\hline 24 & 6058 & 920 \\
\hline
\end{tabular}

Source: Gathered from Sosyomod (10.05.2016)

Comparing daily post hours of the surveyed hospitals and hours of posts "seen" and "interacted" by Facebook fans, the Graphic 3 is inversionally proportional. While hospitals 
share posts between the hours of 9.00 - 14.00, users are interacted with the pages between the hours of 16:00-22:00. By taking this comparison into account, hospitals should manage their Facebook pages in accordance with the current social media dynamics and they should provide instant mutual interaction.

\section{Conclusion}

Digital technologies, including ubiquitous mobile devices, can play a key role in transforming health care system on-demand access to the medical records and powerful clinical decision support tools that empower patients to actively participate in their treatment plans.

In the present paper we explored some of the social media tools in health uses and preferences of Facebook accounts of private and public hospitals in Turkey. Although we found very high levels of ICT and social media use in our sample, limitations in our sample do restrict the generalisability of our findings. We conclude that it is imperative that researchers examine how health consumers use new technologies and target health promotion strategies according to user trends. We cannot assume that everyone has the same level of access to, or experience of, ICTs such as the Internet (O'Mara, 2012). Numerous factors, such as socioeconomic background, education, ethnicity, language, age, gender, communication preferences and digital literacy, health literacy have a significant impact on how the people use new health technologies. In addition to this, these findings lead to build efficient health promotion strategies based on effective health communication.

Acknowledgment: Assistance provided by Mehmet $U c$ and M.Özgür Altuntaş with their data mining tool "Sosyomod" has been a great help in collecting and gathering data.

This paper is financially supported by Galatasaray University Scientific Research Fund within the project no 16.300 .001 


\section{References}

Deloitte Center for Health Solutions, "Healthcare and Life Sciences Predictions 2020" November 2014, http://www2.deloitte.com/uk/en/pages/life-sciences-andhealthcare/articles/healthcare-and-life-sciences-predictions-2020.html

Doğanyiğit, S. \& Y1lmaz, E. "Mobile Health Applications User Trends in Turkey”, Journalism and Mass Communication, January 2015, Vol. 5, No. 1, 45-50.

Fisher, J., \& Clayton, M. (2012). Who gives a tweet: Assessing patients' interest in the use of social media for health care. Worldviews on Evidence-Based Nursing. Retrieved from http://www.ncbi.nlm.nih.gov/pubmed/2243273

Halpert, A., Dalton, C. B., Palsson, O., Morris, C., Hu, Y., Bangdiwala, S., Hankins, J., Norton, N., \& Drossman, D. A. (2008). Patient educational media preferences for information about irritable bowel syndrome (IBS). Digestive Diseases and Sciences, 53, p. 3184.

O’Mara, B. (2012). Social media, digital video and health promotion in a culturally and linguistically diverse Australia. Health Promotion International. doi: 10.1093/heapro/das014, 2012.

Perlmutter, David D. (2008). Blogwars, Oxford University Press; 1 edition, accessed: https://www.questia.com/library/120078716/blogwars.

PwC Health Research Institute, "Healthcare delivery of the future: How digital technology can bridge time and distance between clinicians and consumers" November 2014. pers/pwc-hri-healthcare-technology-and-innovation.pdf

Rettberg, J.W. (2009). “Blogging”, Journal of Communication, Volume 59, Issue 2, 452.

Sundar, S. S. (2008). The MAIN Model: A Heuristic Approach to Understanding Technology Effects on Credibility. The John D. and Catherine T. MacArthur Foundation Series on Digital Media and Learning, 73-100.

Thackeray, R., Neiger, B. L., Hanson, C. L., \& McKenzie, J. F. (2008). Enhancing promotional strategies within social marketing programs: Use of Web 2.0 social media. Health Promotion Practice, 2008.

Yang, S.-U., \& Lim, J. (2009). The effects of blog-mediated public relations on relation trust. Journal of Public Relations Research, 21(3), 341-359. 